\title{
Size-dependent creep of duralumin micro-pillars at room temperature
}

\author{
R. Gu ${ }^{\S}$ and A.H.W. Ngan \\ Department of Mechanical Engineering, The University of Hong Kong, \\ Pokfulam Road, Hong Kong, P.R. China \\ ${ }^{\S}$ Corresponding author (email: gurui @ hku.hk)
}

\begin{abstract}
The strength of aluminum alloy 2025 (duralumin) micro-pillars is known to be significantly higher than that of pure Al micro-pillars of comparable sizes since the precipitates present act as obstacles to trap dislocations within the small sample volume. In this work, the creep behavior of precipitate-hardened duralumin micro-pillars of sizes $\sim 1 \mu \mathrm{m}$ to $\sim 6.5 \mu \mathrm{m}$ is investigated by compression experiments at room temperature. The effects of an internal grain boundary were also investigated by comparing the creep behavior between single crystalline and bi-crystalline micro-pillars. The results reveal that peak aged duralumin pillars, in which the produced precipitates can efficiently block mobile dislocations, show increasingly significant creep with increasing pillar size, with a typical creep rate of $\sim 10^{-4} \mathrm{~s}^{-1}$ which is drastically larger than that of bulk at room temperature. The bi-crystalline pillars creep even faster than the single crystalline counterparts. TEM examination of the deformed microstructures reveals that the creep rate depends on the residual dislocation density, indicating that dislocations are the agents for creep. Theoretical modeling suggests that the steady-state creep rate is proportional to the lifetime of mobile dislocations, which rises with specimen size in the microns range due to the fact that the dislocations are not easily pinned in this range. As the pillar size increases in this range, the dislocations spend longer time in viscous motion across the specimen, hence the retained dislocation density is higher which leads to a higher strain rate according to the Orowan equation. It is expected that this trend of creep rate with specimen size will be reversed for larger specimens, probably in the tens of microns range, when dislocations experience a higher chance of being pinned and immobilized by the precipitates.
\end{abstract}




\section{Keywords}

Creep; Size effect; Dislocations; Grain boundary; Nanoindentation; Precipitation hardening. 


\section{Introduction}

It is well known that micro- and nano-sized metallic single crystals exhibit sizedependent deformation behavior. The most investigated phenomena are the inverse relationship between strength and specimen size (Dimiduk et al., 2005; Dimiduk et al., 2007; Dou and Derby, 2009; Frick et al., 2008; Greer and De Hosson, 2011; Han et al., 2010; Kim et al., 2010; Kim et al., 2012; Lee et al., 2009; Ng and Ngan, 2008b; Sun et al., 2011; Volkert and Lilleodden, 2006; Ye et al., 2011), and jerky flow behavior (Dimiduk et al., 2005; Dimiduk et al., 2007; Dimiduk et al., 2006; Greer and Nix, 2006; Greer et al., 2005; Ng and Ngan, 2008a, b; Shan et al., 2008; Uchic et al., 2004). With the assistance of advanced techniques such as in situ transmission electron microscopy (TEM) (Hemker and Nix, 2008; Oh et al., 2009; Shan et al., 2008) and Laue micro-diffraction (Maass and Uchic, 2012; Maass et al., 2009; Zimmermann et al., 2012), the dislocation structure evolution in nano- and micro- specimens can be visualized, and the physical mechanisms of the unusual deformation behavior are explainable by a number of models. One widely accepted model considers a "dislocation starvation" condition pertinent to submicron crystal volumes (Greer and Nix, 2006; Greer et al., 2005), in which mobile dislocations would easily glide through the crystal leaving the latter in a continuous dislocation-depleted state. The "source truncation" (Parthasarathy et al., 2007; Rao et al., 2007) and "exhaustion hardening" (Akarapu et al., 2010; Norfleet et al., 2008; Rao et al., 2008) models consider that in larger crystals that are microns in size, due to the distribution and operation of dislocation sources in the confined volume, a mean-field condition for forest hardening could not be met.

In order to smooth out the jerky flow, a number of strategies have been proposed to restore the mean-field condition for dislocation interactions by introducing means to trap dislocations within the specimen, including coating (El-Awady et al., 2011; Gu and Ngan, 2012; Jennings et al., 2012; Lee et al., 2013; Ng and Ngan, 2009b; Xu et al., 2013), grain boundary (Burek et al., 2011; Gu et al., 2012; Jang et al., 2011; Kunz et al., 2011; Ng and Ngan, 2009a; Rinaldi et al., 2008; Zhang et al., 2013), nano-twinning (Afanasyev and Sansoz, 2007; Deng and Sansoz, 2009; Jang et al., 2011; Jang et al., 2012) and precipitates(Gu and Ngan, 2013). Somewhat surprisingly, in addition to achieving a smoother flow behavior, the rapid accumulation of dislocations within a small volume can often lead to tremendous strain 
hardening and therefore elevation of the flow stress (Afanasyev and Sansoz, 2007; El-Awady et al., 2011; Gu and Ngan, 2012, 2013; Jang et al., 2011; Jennings et al., 2012; Ng and Ngan, 2009a, b; Zhang et al., 2013), although in the case of introducing a grain boundary to form a bi-crystal, a weakening effect was observed in nano-sized pillars (Kunz et al., 2011) whereas strengthening was observed in micron-sized counterparts ( $\mathrm{Ng}$ and Ngan, 2009a). Our recent study on precipitated duralumin micro-pillars (Gu and Ngan, 2013) shows that strength is improved while size dependence is reduced by the precipitates, when compared with pure Al pillars. However, significant creep was also found in these precipitated duralumin micro-pillars, particularly in relatively larger pillars.

Understanding time-dependent plasticity is very important in engineering applications, and so far, the room-temperature (RT) creep behavior of micro-pillars has been studied in a number of materials. Compression experiments on $\mathrm{Ni}_{3} \mathrm{Al}$ micro-pillars at $\mathrm{RT}$ have revealed an extremely high creep rate relative to that of bulk, which is thought to be due to the surface diffusion at the pillar heads (Afrin and Ngan, 2006). However, single crystalline Al micro-pillars were found to exhibit creep rates two orders of magnitude lower than polycrystalline Al bulk, and this is attributed to the much lower contents of dislocations which are the agents for dislocation creep (Ng and Ngan, 2007). The RT creep of nanocrystalline nickel pillars has also been found to exhibit a reverse relation with the specimen size, with a much larger creep rate than that of bulk due to an increased contribution of free surface (Choi et al., 2013). These observations as a whole suggest that both the external specimen size and internal microstructures can significantly affect the creep behavior of small crystals. However, the effects of these two factors on creep have not been systematically studied yet. In the present study, using duralumin micro-pillars as a model system, the coupled influence on the RT creep of a controlled precipitated microstructure, an introduced grain boundary, as well as external specimen size, was investigated.

\section{Experimental details}


Two bulk slices of aluminum alloy 2025 (Al-4wt\%Cu-1.3wt\%Mg-1.3wt\%Ag-0.6wt\%Mn) were annealed at $500^{\circ} \mathrm{C}$ for 24 hours for homogenization initially. The specimens were then solution heat-treated at $520^{\circ} \mathrm{C}$ for 3 hours in an air furnace, followed by immediate water quench in icy water. The bulk specimens were stretched by $\sim 2 \%$ in a tensile machine before aging treatment. Then, one of the specimens, labeled as the 'RT-aged' hereafter, was exposed at RT for several days without any artificial aging; the other, labeled as 'peak-aged', was aged at peak condition at $170^{\circ} \mathrm{C}$ for 15 hours in a furnace ( $\mathrm{Gu}$ and Ngan, 2013). The two pieces were mechanically polished, and then electro-polished in a 1:4 mixture of nitric acid and methanol at $30^{\circ} \mathrm{C}$ and $15 \mathrm{~V}$ for 30 seconds. Afterwards, Electron Back Scattered Diffraction (EBSD) was carried out on both pieces to identify large grains with diameter $>80 \mu \mathrm{m}$ and orientation $\sim[101]$, in which micro-pillars were fabricated by a Quanta 200 3D Dual Beam FIB/SEM (FIB) system. Micro-pillars of diameters $\sim 6.5 \mu \mathrm{m}, \sim 3.5 \mu \mathrm{m}$ and $\sim 1.0 \mu \mathrm{m}$, all with a diameter-to-height ratio of $\sim 1: 3$, were made by a series of concentric annular-patterned FIB milling with decreasing currents at an ion beam voltage of $30 \mathrm{kV}$. The fabricated micro-pillars were slightly tapered $\sim 3^{\circ}$ due to the defocused ion beam milling, and the diameters of pillars were taken at mid-height. While most pillars machined this way were single crystalline, some were bi-crystalline with an initially subsurface grain boundary passing through the body of pillar. All pillars were subjected to creep testing at RT in an Agilent G200 Nanoindenter with a flat-ended diamond punch of diameter $8.5 \mu \mathrm{m}$, which was fabricated from a diamond Berkovich tip also by FIB milling. The creep tests were performed in a load controlled manner, in which the applied load was raised to a peak value and held for 200 seconds before unloading. The loading and unloading rate was the same at $\sim 12 \mathrm{MPas}^{-1}$, so that the strain rate during this stage could remain at $\sim 10^{-3} \mathrm{~s}^{-1}$. Thermal drift was controlled at within $0.5 \mathrm{~nm} / \mathrm{s}$. The deformed appearances of micro-pillars after creep tests were imaged by scanning electron microscopy (SEM) in a LEO1530 microscope. Finally the deformed duralumin pillars were characterized by transmission election microscope (TEM) in order to examine their crystal structures as well as dislocation distributions. Longitudinal TEM samples running along the long axis of the pillars were prepared by FIB milling on both sides of the pillars to reduce the thickness into $\sim 1 \mu \mathrm{m}$, then welded onto an in situ Omniprobe by tungsten deposition, followed by cutting off from the bulk. The samples were welded into TEM copper grids by tungsten deposition and cut from the Omniprobe, and finally thinned down to $\sim 150 \mathrm{~nm}$ 
thickness by FIB milling for electron transparency. TEM characterization was carried out in a Philips Tecnai microscope operating at 200kV.

\section{Results and analysis}

\subsection{Single crystalline micro-pillars}

The single crystalline duralumin micro-pillars of diameters $1 \mu \mathrm{m}, 3.5 \mu \mathrm{m}$ and $6.5 \mu \mathrm{m}$ were loaded to a peak value and held for 200 seconds. During the hold, the axial strain increased with time as shown in Figure 1(a-b), where different pillar sizes were labeled by different colors. The maximum peak load varied from $50 \mathrm{MPa}$ to $125 \mathrm{MPa}$, which is lower than the yield strength of duralumin micro-pillars of similar sizes (Gu and Ngan, 2013). For all the RT-aged micro-pillars in the same test condition, the stress-strain curves for pillars of different sizes are almost coincident both at the loading/unloading stage and the holding regime with slight scattering, and do not show any obvious size-dependent trend. However, for the peak-aged micro-pillars, the external specimen size can significantly affect the stress-strain curves. During the initial loading stage, the large $6.5 \mu \mathrm{m}$ pillars were much softer than the smaller pillars, and this has already been discussed separately ( $\mathrm{Gu}$ and Ngan, 2013). The increased strain during the holding regime also depends significantly on the specimen size as well as the holding stress. It is obvious that larger pillars under higher stress can creep more significantly. The size dependent stress-strain behavior can also indicate that the softening in the loading stage was not produced by misalignment during tests which can lead to elastic softening, because the latter should lead to scattered modulus independent of the specimen size. Figure 1(c) summarizes the relation between the increased strain during holding and the applied stress. For the RT-aged pillars, the increased strain shows no obvious correlation with the applied stress and their external size, and the mean value for all tests is $\sim 0.004$. For the peak-aged micro-pillars, the strain in the holding stage obviously depends on the applied stress and external size. As the applied stress varied from $\sim 50 \mathrm{MPa}$ to $\sim 125 \mathrm{MPa}$, the increased strain for the $1.0 \mu \mathrm{m}$ pillars rose from 0.004 to 0.013 and that for the $6.5 \mu \mathrm{m}$ ones rose from 0.03 to 0.05 respectively, while the $3.5 \mu \mathrm{m}$ pillars exhibit an intermediate value. As the drift rate for all the tests was controlled to a similar value, for the 
peak-aged micro-pillars the significant displacement recorded during peak load holding should represent their significant creep behavior.

Figure 2 (a-b) shows details of the creep behavior of the peak-aged single crystalline duralumin micro-pillars. As shown in Figure 2(a), the 6.5 $\mu \mathrm{m}$ micro-pillars exhibited the usual transient creep regime where the strain increases rapidly with time, and then keeps on increasing with time almost linearly, indicating that a quasi-steady state regime has been reached, although the holding time is only 200 seconds. As for the $1.0 \mu \mathrm{m}$ pillars, the demarcation of the two regimes is more ambiguous since the strain only grows slightly with time. Pop-in occasionally occurred on the strain curve when the applied stress was larger than $100 \mathrm{MPa}$ which is close to their yield strength(Gu and Ngan, 2013), suggesting the sudden generation of mobile dislocations at that moment(Li and Ngan, 2010; Ng and Ngan, 2007).

The quasi-steady strain rate $\dot{\varepsilon}$ was estimated as the average value of the strain rate between the holding time at 190s and 200s, and its relation with the applied stress is shown in Figure 2(b). During the hold, strain rate $\dot{\varepsilon}$ is composed of the creep rate $\dot{\varepsilon}_{c}$, thermal drift rate $\dot{\varepsilon}_{t h}$ and strain rate $\dot{\varepsilon}_{n}$ caused by environment noise, i.e. $\dot{\varepsilon}=\dot{\varepsilon}_{c}+\dot{\varepsilon}_{t h}+\dot{\varepsilon}_{n}$. As the drift rate during the tests was controlled at within $0.5 \mathrm{nms}^{-1}$, this would lead to a fictitious strain rate $\dot{\varepsilon}_{t h}$ the upper limit of which would be $2.5 \times 10^{-5} \mathrm{~S}^{-1}, 5 \times 10^{-5} \mathrm{~s}^{-1}$ and $1.7 \times 10^{-4} \mathrm{~s}^{-1}$ respectively for the $6.5 \mu \mathrm{m}, 3.5 \mu \mathrm{m}$ and $1.0 \mu \mathrm{m}$ micro-pillars, respectively, according to the diameter to height ratio of $\sim$ 1:3. However, Figure 2(b) shows an opposite trend of $\dot{\varepsilon}$ increasing with the pillar size. For the largest $6.5 \mu \mathrm{m}$ pillars, the strain rate $\dot{\varepsilon}$ increases with the applied stress from $\sim 1.0 \times 10^{-4} \mathrm{~s}^{-1}$ to $\sim 2.0 \times 10^{-4} \mathrm{~s}^{-1}$, which is much larger than the upper limit value of $\dot{\varepsilon}_{t h}$, confirming again that creep deformation was clearly significant in the $6.5 \mu \mathrm{m}$ pillars. This observation is very different from pure aluminum micro-pillars in the size range of $\sim 4 \mu \mathrm{m}$ to $\sim 6.5 \mu \mathrm{m}$, where the creep strain rate was almost independent of stress and was in the order of $\sim 10^{-7} \mathrm{~s}^{-1}$ to $\sim 10^{-6} \mathrm{~s}^{-1}$ ( $\mathrm{Ng}$ and Ngan, 2007). For the peak-aged $1.0 \mu \mathrm{m}$ and $3.5 \mu \mathrm{m}$ pillars, the trend that the quasi-steady strain rate $\dot{\varepsilon}$ increases with the applied stress becomes less obvious. The error bars in Figure 2(b) stand for one standard deviation from the mean value, and these are relatively wider for these two groups than the $6.5 \mu \mathrm{m}$ group. This may be attributed to two reasons: (i) the environment noise affects the calculated strain rate of the smaller pillars more significantly, and (ii) the stochastic 
fluctuations of the microstructures, in terms of the distribution of dislocations and precipitates, are more in smaller crystal volumes due to the breakdown of the mean-field effect. Nevertheless it is still obvious that the smaller pillars exhibit lower quasi-steady creep rate $\dot{\varepsilon}_{c}$, despite that they are associated with larger drift rate $\dot{\varepsilon}_{t h}$. To conclude, creep deformation is size dependent in the peak-aged duralumin micro-pillars, and it becomes much more significant for larger pillars in the micron scale.

The creep behavior of the peak-aged $6.5 \mu \mathrm{m}$ pillars was studied, with the applied stress in the holding regime increasing up to $350 \mathrm{MPa}$. As the drift rate $\dot{\varepsilon}_{t h}$ and noise disturbance $\dot{\varepsilon}_{n}$ are much smaller than the quasi-steady strain rate $\dot{\varepsilon}$, the quasi-steady creep rate $\dot{\varepsilon}_{c}$ is approximately equal to $\dot{\varepsilon}$, and is shown in Figure 3. It is found that, as similar to the creep behavior of duralumin bulk, $\dot{\varepsilon}_{c}$ increases with the applied stress $\sigma$ in a power-law manner $\dot{\varepsilon}_{c} \propto \sigma^{m}$, where $m=0.55$ is much smaller than that of bulk which is often in the range of $\sim 3$ to 8 (Nabarro and Villiers, 1995). The difference is thought to be a result of dislocation nucleation and depletion in the micro-crystals, as will be discussed later.

\subsection{Bi-crystalline micro-pillars}

The creep behavior of bi-crystalline $6.5 \mu \mathrm{m}$ pillars was also investigated, and their stressstrain behavior is shown in Figure 4(a). Compared with the single crystalline case in Figure 1(ab), it is obvious that for both the RT-aged and peak-aged cases, the bi-crystalline pillars are softer during the initial loading stage and exhibit large strain increments in the holding stage, and these are particularly so for the peak-aged bi-crystalline pillars which show very significant softening compared to the single crystalline counterparts. The stress-strain curves in the loading stage in Figure 4(a) are uniform with slight scattering for the same kind of specimens, proving again that the softening is not introduced by misalignment between the specimens and the flat punch. The relation of quasi-steady strain rate and applied stress for the $6.5 \mu \mathrm{m}$ pillars is shown in Figure 4(b). For both the RT-aged and peak-aged specimens, it is obvious that the bicrystalline pillars creep much faster compared to the single crystalline counterparts under the same test condition, and the quasi-steady strain rate monotonously increases with stress at a 
much higher rate than the single crystalline pillars. In a word, an introduced grain boundary in the duralumin micro-pillars can lead to significant softening and enhanced creep when compared to monolithic pillars, even for the RT-aged pillars in which the precipitate size is much smaller. This result is contrary to pure Al micro-pillars (Ng and Ngan, 2007) of similar sizes, where an introduced grain boundary leads to higher strength and work-hardening rate.

\subsection{SEM and TEM examinations}

Figure 5(a-b) is the deformed appearances of bi-crystalline $6.5 \mu \mathrm{m}$ pillars aged at RT and peak condition, corresponding to Figure 4 with a final strain of $\sim 0.035$ and $\sim 0.134$ respectively. Compared with the pure aluminum pillars of diameter 5-6 $\mu \mathrm{m}$ after creep test $(\mathrm{Ng}$ and $\mathrm{Ngan}$, 2007), it is surprising that the deformed duralumin micro-pillars did not show any obvious slip bands around its surface. Their surface is very smooth except for a flaw where a grain boundary is located. The stress-strain curve in Figure 4 shows that the whole deformation process is very smooth and continuous without any pop-ins that happen in the case of pure aluminum, suggesting that dislocations do not in general zip through the pillar thickness to produce slip steps on the free surface, as is the case in pure Al pillars.

The microstructures of deformed duralumin pillars were characterized by TEM. All of the TEM samples were fabricated from $6.5 \mu \mathrm{m}$ duralumin pillars after creep tests with stress $\sim 100 \mathrm{MPa}$. The $g$ vectors for two-beam conditions were chosen to give the most abundant visible dislocations under Bragg conditions. Although ion damage during FIB preparation was inevitable in the TEM samples, the dislocation distribution in the specimens, and in particular its variation with pillar size and precipitation microstructure, was still obvious. Figure 6(a-c) show the TEM images of deformed single crystalline duralumin pillars. In the TEM montage of the RT-aged pillar shown in Figure 6(a), dislocations with short lengths are seen tangled together and accumulating to a much higher density in the top part of the pillar, where the local stress should be slightly higher due to the slight tapered geometry of the pillar. Rod-shape dispersoids of $T$ phase $\left(\mathrm{Al}_{20} \mathrm{Cu}_{2} \mathrm{Mn}_{3}\right)$ 0.2-0.5 $\mu \mathrm{m}$ long are seen distributed randomly in the pillar, which is not responsible for strengthening of the material (Wang and Starink, 2005). Figure 6(b) and 6(c) 
show representative high-magnification TEM images of a RT-aged and a peak-aged pillar with corresponding final strain of 0.013 and 0.056 respectively, taken close to the top of the pillars. Bowed-out dislocations are seen tangled in the RT-aged pillar in Figure 6(b), indicating Orowan bowing mechanism was operative in the specimen with aging precipitates of $\mathrm{Mg}-\mathrm{Cu}$ co-clusters in nano-size(Austin and McDowell, 2011; Starink and Wang, 2009; Wang and Starink, 2005). While in the peak-aged pillar in Figure 6(c), dislocations are zigzagged and jammed by coexisting precipitates of non-coherent lath-shaped $S$ phase $\left(\mathrm{Al}_{2} \mathrm{CuMg}\right)$ and coherent GuinierPreston-Bagaryatsky (GPB) zones (Wang and Starink, 2005, 2007) in a much denser state. The dislocation density $\rho$ was estimated by the line-intercept method, in which $\rho$ is calculated as $\rho \approx 1 / d^{2}$ where $d$ is the average spacing between dislocation segments. It is obvious that dislocations distribute more densely in the peak-aged pillar with an average density $\rho \sim 1.0 \times$ $10^{14} \mathrm{~m}^{-2}$, an order of magnitude higher than the RT-aged one with $\rho \sim 3.0 \times 10^{13} \mathrm{~m}^{-2}$. Although the two pillars in Figure 6(b-c) did not have the same final strain, during steady-state creep the dislocation density should also reach a steady state (Smallman and Ngan, 2007) and so these estimates of $\rho$ here should be representative of the steady-state creep behavior. The results reveal that in the single crystalline pillars of $6.5 \mu \mathrm{m}$ diameter, the precipitates in the peak-aged condition are much more effective in slowing down mobile dislocations than the RT-aged condition, so that the former exhibits a higher residual dislocation density after deformation.

Figure 7(a-d) show details of the TEM characterization of the RT- and peak-aged bicrystalline $6.5 \mu \mathrm{m}$ duralumin pillars deformed in similar creep tests up to final strains 0.035 and 0.134 respectively. The TEM montages of the upper parts of the pillars in Figure 7(a,c) show that a grain boundary passes through the pillars and dislocations are more abundant than the case shown in Figure 6(a). Figure 7(b) and (d) are representative TEM images on the top grain close to the top of the pillars, from which the dislocation density is estimated as $\rho \sim 4.0 \times 10^{13} \mathrm{~m}^{-2}$ and $\rho \sim 2.0 \times 10^{14} \mathrm{~m}^{-2}$, respectively. As similar to the case of pure Al bi-crystalline pillars $(\mathrm{Ng}$ and Ngan, 2009a), a grain boundary can act not only as nucleation sites of dislocations, but also a barrier for mobile dislocations, so it is not surprising that the deformed bi-crystalline pillars show a higher dislocation density than the single crystalline case. 


\section{Discussions}

\subsection{Microstructural effects on creep behavior}

Figure 1(a-c) show that the peak-aged duralumin micro-pillars creep much faster than the RT-aged counterparts, indicating that the precipitates present in the specimen is an important factor for creep. The precipitates in the specimen can act as obstacles for dislocation movement, so as to impede their elimination at free surfaces. The major precipitates in peak-aged duralumin are non-coherent $S$ phase particles $\left(\mathrm{Al}_{2} \mathrm{CuMg}\right)$ with a submicron size (Wang and Starink, 2005). Compared with the precipitates produced under RT ageing, they are much larger but wider in spacing (Wang and Starink, 2005), therefore for a micro-pillar with a large enough size $D$ ( e.g. $D>5 \mu \mathrm{m}$ ), dislocation motion in the peak-aged case is more likely to be slower due to the precipitates, resulting in higher dislocation contents in the deformed crystal (Gu and Ngan, 2013). In a small size pillar such as $D \sim 1 \mu \mathrm{m}$, for both the RT-aged and peak-aged case, mobile dislocations have more opportunities to zip through the confined volumes, leading to a lower dislocation density in the deformed state (Gu and Ngan, 2013). Precipitates therefore play the role to accumulate dislocations which are the agents for creep, and so it is not surprising that with increasing crystal size, peak aged micro-pillars creep faster than RT-aged counterparts as shown in Figure 1. The fact that creep of micron-sized crystal volumes at RT is intrinsically tied to pre-existing dislocations has been demonstrated earlier in nanoindentation experiments on pure $\mathrm{Al}$ at constant loads (Feng and Ngan, 2001)

On the other hand, when a grain boundary is introduced, duralumin bi-crystalline micropillars can creep even faster than the single crystalline pillars at both the RT-aged and peak-aged conditions, as shown in Figure 4(a-b). It has been found that the embedded Ga atoms on the aluminum grain boundary introduced by FIB milling can cause grain boundary weakening and intergranular embrittlement (Zhang et al., 2006). However, the deformation behavior of pure $\mathrm{Al}$ bi-crystal pillars with similar sizes (Ng and Ngan, 2009a) shows that the presence of a grain boundary can increase the strength of micro-pillars due to the storage of dislocations to a high density inside, suggesting that the weakening effect by the embedded $\mathrm{Ga}$ at the grain boundary is limited. TEM examination of the deformed state reveals that the dislocation density in the bicrystalline case is much higher, especially for the peak-aged case, suggesting that like the pure 
aluminum case ( $\mathrm{Ng}$ and $\mathrm{Ngan}, 2009 \mathrm{a}$ ), the grain boundary in the duralumin micro-pillars may not just be a source for dislocation nucleation, but can also be a barrier for mobile dislocations to prevent them from leaving the crystal, thus retaining a high content of dislocations inside the crystal, which are the agents for creep. The grain boundary may introduce other effects on creep deformation, such as grain-boundary diffusion and sliding, as shown in another investigation on RT creep of nanocrystalline nickel pillars (Choi et al., 2013), but the results there indicated a reversed size dependent creep behavior, due to the increased contributions of free surfaces in smaller crystals. Therefore it is suggested that the creep of the duralumin bi-crystal micro-pillars here is dislocation, rather than grain-boundary, controlled. Figure 8 summarizes the estimated dislocation density in the deformed $6.5 \mu \mathrm{m}$ duralumin pillars under the same testing condition, together with their quasi-steady creep rate $\dot{\varepsilon}_{c}$. Although the dislocation density $\rho$ was a rough estimate from $<111>$ Bragg conditions, it is still obvious that $\dot{\varepsilon}_{c}$ increases with $\rho$ with a strong correlation, indicating again that creep in the duralumin micro-pillars is dislocation controlled.

\subsection{Size effect on creep behavior}

Another significant observation can be made by comparing the creep behavior between duralumin bulk and micro-pillars. Duralumin is an engineering material with wide applications (Dunnwald and ElMagd, 1996; Kazanjian et al., 1997; Kloc et al., 1996; Lumley et al., 2002), as it exhibits enhanced strength as well as better creep performance than pure $\mathrm{Al}$, and the creep rate at stresses ranging from dozens to several hundreds of MPa is just about $10^{-10} \sim 10^{-7} \mathrm{~s}^{-1}$ even at elevated temperatures $(400 \mathrm{~K} \sim 600 \mathrm{~K})$. However the above observations reveal that peak-aged duralumin micro-pillars creep significantly at RT, and even much faster than Al bulk and Al micro-pillars (Ng and Ngan, 2007). A similar observation arises in nano-crystalline nickel pillars of submicron sizes which creep much faster than bulk in RT with a creep rate 4 to 5 orders of magnitude higher than that of bulk (Choi et al., 2013), and this is attributed to the large proportion of free surface in the small pillar case (Choi et al., 2013). In the case of duralumin micro-pillars, the external size also plays an important role in their creep behavior. As mentioned above, the density of dislocations, which are the agents for creep, is controlled by the specimen size. In a small crystal, a mobile dislocation is more likely to zip through the confined volume 
without multiplication or being slowed down or pinned by precipitate particles, so compared with a large micro-pillar, it exhibits a lower residual dislocation density, as demonstrated by TEM examination (Gu and Ngan, 2013), and also creeps less as shown in Figure 2.

To quantitatively estimate the size effect on creep of micro-pillars, a model is developed here. According to the Orowan equation, the strain rate $\dot{\varepsilon}_{S S}$ during the steady state of a creep test can be written as

$$
\dot{\varepsilon}_{s S}=\rho_{m} \bar{v} b
$$

where $\rho_{m}$, and $\bar{v}$ respectively represent the mobile dislocation density and average velocity, and $b$ is the Burgers vector. Very generally, the rate of mobile dislocation density $\dot{\rho}_{m}$ evolves according to

$$
\dot{\rho}_{m}=\dot{\rho}^{+}+\dot{\rho}^{-}
$$

where $\dot{\rho}^{+}$and $\dot{\rho}^{-}$are the production and annihilation rates of the mobile dislocations, and $\dot{\rho}^{+}$ here includes both the nucleation as well as multiplication rate. In a micro-pillar, fresh dislocations can be produced from the free surface or by sources inside, and both mechanisms should operate more rapidly at a higher stress level. The production rate $\dot{N}$ of dislocations has been proposed as a power-law form (Ngan and Ng, 2010; Nix and Lee 2011)

$$
\dot{N} \propto \sigma^{m}
$$

and with this, the dislocation generation rate would be

$$
\dot{\rho}^{+}=C \sigma^{m}
$$

where $C$ is a material constant. The dislocation annihilation rate can be supposed to obey first-or der kinetics so that it can be written as:

$$
\dot{\rho}^{-}=-\frac{\rho_{m}}{\Gamma}
$$

where $\Gamma$ is the average life time of mobile dislocations (Nix and Lee 2011). 
When a mobile dislocation glides in a precipitated crystal, it may encounter precipitate particles. Upon interacting with such a particle, the dislocation may either overcome it by some bypassing mechanisms such as cross-slip (Poirier, 1985), or may be pinned and immobilized by it. A survival probability $F(L)$ is introduced here, which is the probability that a mobile dislocation has not been pinned by precipitates yet after gliding for a distance $L$. For obvious reasons, $F(L)$ should be monotonically decreasing with $L$, varying from 1 to 0 when $L$ approaches infinity. A convenient phenomenological form of $F(L)$ can be:

$$
F(L)=\exp \left(-\alpha L^{\beta}\right)
$$

where $\alpha, \beta>0$. If the dislocation is able to overcome the particles it encounters during a travel distance $L$, then the life time $\Gamma$ in eqn. (5) above should be the sum of the time $\Gamma_{g}$ for gliding the distance $L$, and the time $\Gamma_{o}$ for overcoming the particles, i.e.

$$
\Gamma=\Gamma_{g}+\Gamma_{o}
$$

It is reasonable to assume that $\Gamma_{o}$ is linearly proportional to $\Gamma_{g}$ during a given distance travelled, as the distribution of precipitates is relatively homogeneous in the duralumin. Therefore, equation (7) can be written as $\Gamma=K \times \Gamma_{g}$, where $K$ is a coefficient that represents the difficulty for dislocations to glide a given distance in the material, and so $K$ for the peak-aged duralumin should be much larger than that in the RT-aged case. In a micro-crystal with thickness $D$, a mobile dislocation can either glide through the specimen thickness $D$ and finally annihilate at a free surface, or be immobilized by precipitate pinning and other ways. Therefore the average life time $\Gamma$ of mobile dislocations is

$$
\Gamma=K \times \Gamma_{g}=K \times\left\{\frac{D}{\bar{v}} \times F(D)+\frac{d}{\bar{v}} \times[1-F(D)]\right\},
$$

where $d$ is the mean free path of a dislocation between blockage by precipitates or immobilization events of other types. In this equation, the first term $K \times \frac{D}{\bar{v}} \times F(D)$ represents those dislocations which can zip through the pillar's thickness $D$ without being captured by the precipitates, and the second term $K \times \frac{d}{\bar{v}} \times[1-F(D)]$ represents those which are immobilized 
by the precipitates or things alike. In the steady state $\dot{\rho}_{m}=0$, so eqns. (2), (4), (5) and (8) can be developed into

$$
\rho_{m}=\frac{C \prime \sigma^{m}}{\bar{v}}\{D \times F(D)+d \times[1-F(D)]\}
$$

and from eqn. (1), the creep rate then becomes

$$
\dot{\varepsilon}_{S S}=C^{\prime} \sigma^{m}\{D \times F(D)+d \times[1-F(D)]\}
$$

where $C^{\prime}=K C b$.

In the case of duralumin, we suppose $d$ to be a constant for a given aged condition. The parameter $m$ in Equation (10) corresponds to the experimental results in Figure 3 where $m=$ 0.55. Other parameters in Equation (10) can be obtained by fitting to experimental results in Figure 2(b), which gives $\alpha=0.025, \beta=0.86, d=1.43 \mu \mathrm{m} \quad$ and $C^{\prime}=2.1 \times 10^{-6}(\mu \mathrm{ms})^{-1}(\mathrm{MPa})^{-0.55}$. The result shows that in Equation (10), the second term involving $d$ weighs no more than $\sim 3 \%$ of the first term, suggesting that slight deviations in the value of $d$ would not affect the calculated $\dot{\varepsilon}_{S S}$ significantly, so that the assumption of a constant $d$ is reasonable. It should also be noticed that $d$ is the mean free path of a dislocation between pinning points, rather than the spacing of precipitates, because a gliding mobile dislocation may have opportunities to overcome the precipitates and keep on moving in the slip plane. Therefore, it is reasonable that $d$ is larger than the precipitates spacing of a few dozens to hundreds of nanometers. The theoretical curves are shown in Figure 2(b) when $\dot{\varepsilon}_{s}$ is taken as the strain rate $\dot{\varepsilon}$, and it can be seen that one set of $\alpha, \beta, d$ and $C^{\prime}$ parameters can fit the $\dot{\varepsilon}_{s S}-\sigma$ relation for three different pillar sizes $D$.

The fact that the experimental trends in Figure 2(b) can be described well by the model above indicates the validity of the latter. In a solute rich environment, the viscous motion of the dislocations, rather than strain hardening, controls the deformation rate, which increases as the quantity of mobile dislocations increases according to eqn. (1). In this picture, as Eqns. (9) and (10) show, the dependence of the creep rate on stress and pillar size as seen in Figure 2(b) is simply the effect of these two factors on the mobile dislocation density, which also agrees well with the observation from Figure 8 that the measured creep rate exhibits a good correlation with 
the measured dislocation density. In the model, the stress dependence of the mobile dislocation density arises from the enhanced dislocation nucleation at higher stress, and although the powerlaw form in eqn. (4) is empirical, such a form was found previously (Ngan and Ng, 2010; Nix and Lee 2011) to be able to produce predictions agreeing well with experiments.

The size dependence of the dislocation density, on the other hand, arises from the effect of specimen size on the lifetime $\Gamma$ of mobile dislocations inside the pillar, in a steady state where production balances annihilation. In such a steady state at a given stress level (which leads to production at a particular rate), eqns. (2), (4) and (5) give $\rho_{m}=C \sigma^{m} \Gamma$, i.e. a longer mobile lifetime would correspond to more mobile dislocations remaining in the pillar. From eqns. (6) and (8), as the pillar size $D$ increases, the mobile lifetime $\Gamma$ first increases, since dislocations take longer time to travel out of a larger specimen. Beyond a critical value of $D$, which is approximately $(\alpha \beta)^{-1 / \beta}, \Gamma$ drops towards an asymptotic value of $K d / \bar{v}$ representing the bulk behavior, due to the fact that now the dislocations have higher chance of becoming pinned by the precipitates and no longer contributing to the strain rate, before they can travel out of the pillar. There is therefore an optimal value of $D$ of $\approx(\alpha \beta)^{-1 / \beta}$ at which the mobile lifetime of dislocations is the longest, and, according to eqns. (9) and (10), the mobile dislocation density and the creep rate are also the highest. Using the parameters concluded above, such a critical value of $D$ is $\sim 90 \mu \mathrm{m}$ in the present peak-aged alloy, which is much larger than the pillar sizes from $1.0 \mu \mathrm{m}$ to $6.5 \mu \mathrm{m}$ used in the present experiments. For this reason, the creep rate in the present experiments increases monotonically with $D$, as Figure 2(b) shows.

Equation (6) also shows that, for pillar size $D$ ranging from $1.0 \mu \mathrm{m}$ to $6.5 \mu \mathrm{m}$, the value of $F(D)$ is larger than 0.88 , revealing that in the peak aged duralumin micro-pillars, most of the mobile dislocations can overcome the precipitates and keep on gliding even when the precipitate particles are densely distributed. The counted dislocation densities presented in Figure 8 should therefore be mobile densities contributing to the creep rate. As the experiments were carried out at room temperature $\left(0.3 \mathrm{~T}_{\mathrm{m}}\right)$, one possible mechanism of overcoming obstacles is cross-slip of screw dislocations, which is known to play an important role in creep of aluminum at intermediate temperatures $\left(0.25 \mathrm{~T}_{\mathrm{m}}-0.5 \mathrm{~T}_{\mathrm{m}}\right)$ (Poirier, 1985). Another point from Equation (10) is that $m$ in the power law form is only 0.55 , which is much lower than the $3 \sim 8$ for bulk creep 
(Nabarro and Villiers, 1995). The difference may be due to the dislocation nucleation rate in Equation (4). In a small crystal, dislocations are likely to nucleate from the free surface under stress, then glide and finally eliminate at a free surface on another side. Therefore, the stress dependence of the creep rate can be entirely different in the case of micro-crystals.

\section{Conclusions}

In this work, the size dependent creep behavior of precipitate-hardened duralumin micropillars was studied at RT. Significant creep was observed in peak-aged micro-pillars, with creep rate on the order of $\sim 10^{-4} \mathrm{~s}^{-1}$ and increases with the pillar size, while RT-aged micro-pillars did not show any obvious creep under the same test conditions. The effect of an introduced grain boundary was also investigated on bi-crystalline duralumin micro-pillars, which exhibit even faster creep. TEM characterization on the deformed micro-pillars revealed that their steady-state dislocation density correlates well with the creep rate, indicating that dislocations are the agents for creep. Higher dislocation densities are noted in the bi-crystalline micro-pillars, suggesting that the grain boundary may not only produce dislocations but also act as a barrier to prevent them leaving the crystal. These results suggest that the presence of strong precipitates or an internal grain boundary can effectively retain dislocations especially in larger micro-pillars, and the resultant increased dislocation density then speeds up creep under constant stress. A theoretical model suggests that for specimen sizes in the microns range, dislocations are not easily pinned by the precipitates, but in a larger specimen, they spend longer time traveling across the specimen. The retained dislocation density is therefore higher in a larger specimen, which leads to a higher creep rate according to the Orowan equation. It is expected that the trend of creep rate vs specimen size will be reversed for larger specimens, probably in the tens of microns range, when dislocations experience a higher chance of being pinned and immobilized by the precipitates.

\section{Acknowledgement}

The work described in this paper was supported by funding from the Research Grants Council (Project No. 7159/10E) and the University Grants Committee (Project No. SEG-HKU06) 
of the Hong Kong Special Administration Region, as well as the Kingboard Endowed Professorship. We also thank the Electron Microscope Unit of HKU for their assistance. 


\section{Figure Captions}

Figure 1. Collective stress-strain curves of (a) RT-aged and (b) peak-aged single crystalline micro-pillars from uniaxial compression tests. The holding time at peak value is 200 seconds for all the tests. (c) The increased strain with applied stress during holding stage.

Figure 2 Correlation of (a) strain versus holding time and (b) quasi-steady strain rate versus applied stress during creep tests for peak-aged duralumin micro-pillars of different sizes.

Figure 3 The variation of quasi-steady creep rate with stress for peak-aged single crystalline $6.5 \mu \mathrm{m}$ pillars during the holding regime.

Figure 4 (a)Stress-strain curves of bi-crystalline $6.5 \mu \mathrm{m}$ pillars fabricated on RT-aged and peakaged duralumin bulk. The holding time at peak loading is 200 seconds for all the tests. (b) Quasisteady strain rate versus applied stress during creep tests.

Figure 5 Deformed SEM images of duralumin bi-crystalline $6.5 \mu \mathrm{m}$ pillars, aged at (a) RT and (b) peak condition respectively, which were undertaken at $30^{\circ}$ tilting. Both of the micro-pillars were deformed after creep tests at $\sim 100 \mathrm{MPa}$.

Figure 6 (a) Bright-field TEM montages of a single crystalline $6.5 \mu \mathrm{m}$ duralumin pillar aged at RT. (b) and (c) are high magnification, localized TEM images of single crystalline $6.5 \mu \mathrm{m}$ pillars aged at RT and peak conditions respectively, and the corresponding final strain are 0.013 and 0.056 for (b) and (c). 
Figure 7 (a) and (c) are bright-field TEM montages of bi-crystalline $6.5 \mu \mathrm{m}$ pillars aged at RT and peak conditions respectively, with corresponding final strain of 0.035 and 0.134 . (c) and (d) are high-magnification, local TEM images of the top grain close to pillar's top, corresponding to (a) and (c) respectively.

Figure 8 Estimated dislocation densities in duralumin $6.5 \mu \mathrm{m}$ pillars crept at $\sim 100 \mathrm{MPa}$, in comparison with the quasi-steady creep rate. 


\section{Figures}

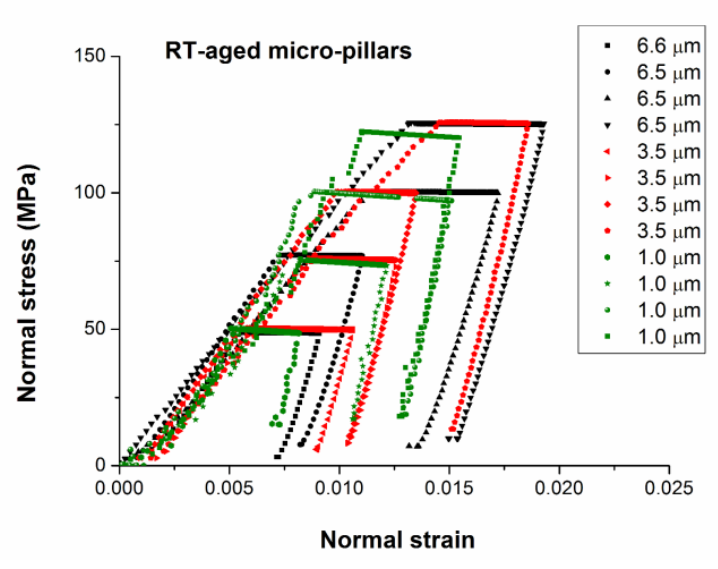

(a)

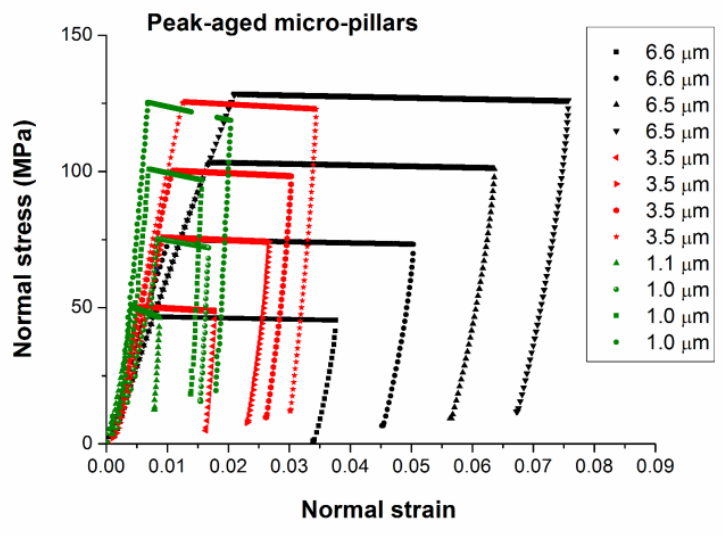

(b)

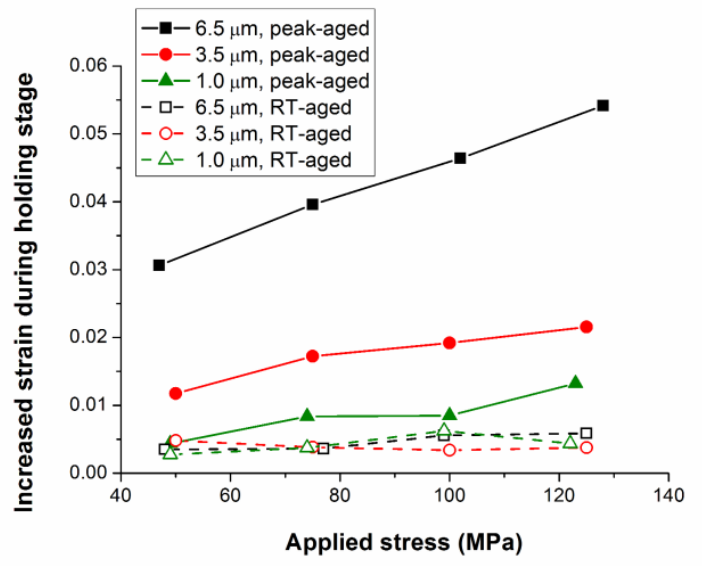

(c)

Figure 1. Collective stress-strain curves of (a) RT-aged and (b) peak-aged single crystalline micro-pillars from uniaxial compression tests. The holding time at peak value is 200 seconds for all the tests. (c) The increased strain with applied stress during holding stage. 


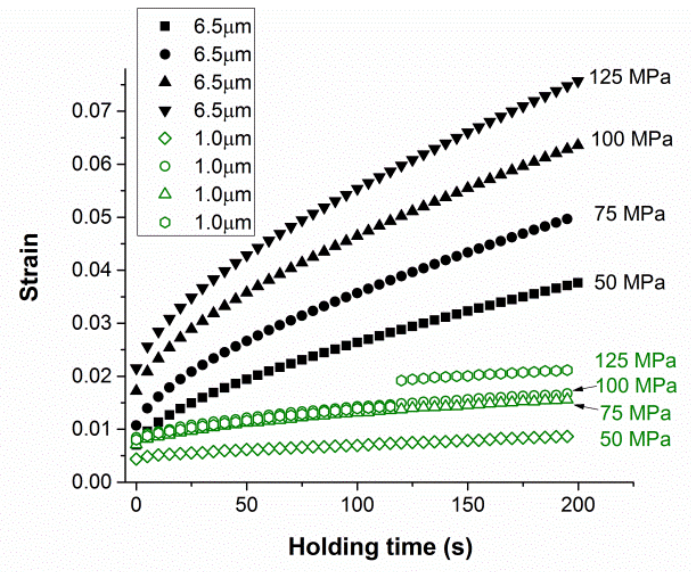

(a)

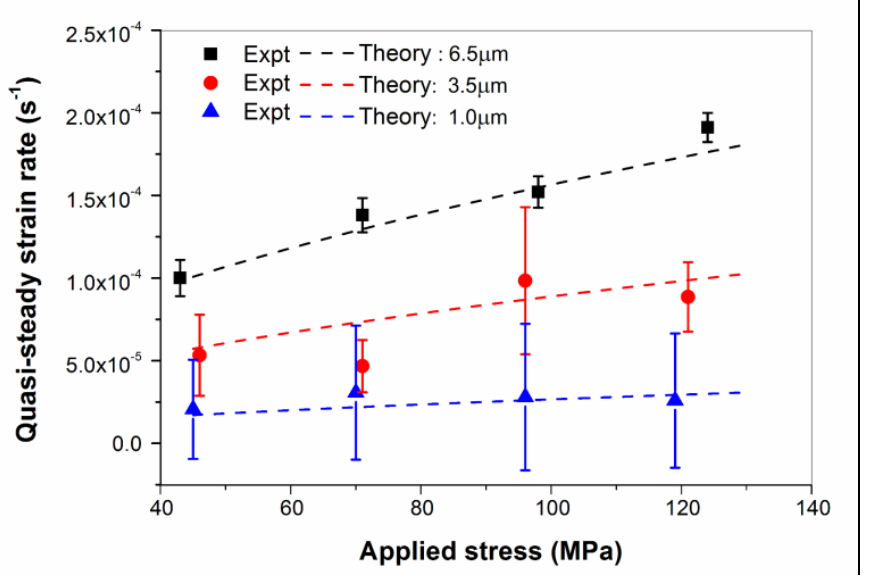

(b)

Figure 2 Correlation of (a) strain versus holding time and (b) quasi-steady strain rate versus applied stress during creep tests for peak-aged duralumin micro-pillars of different sizes.

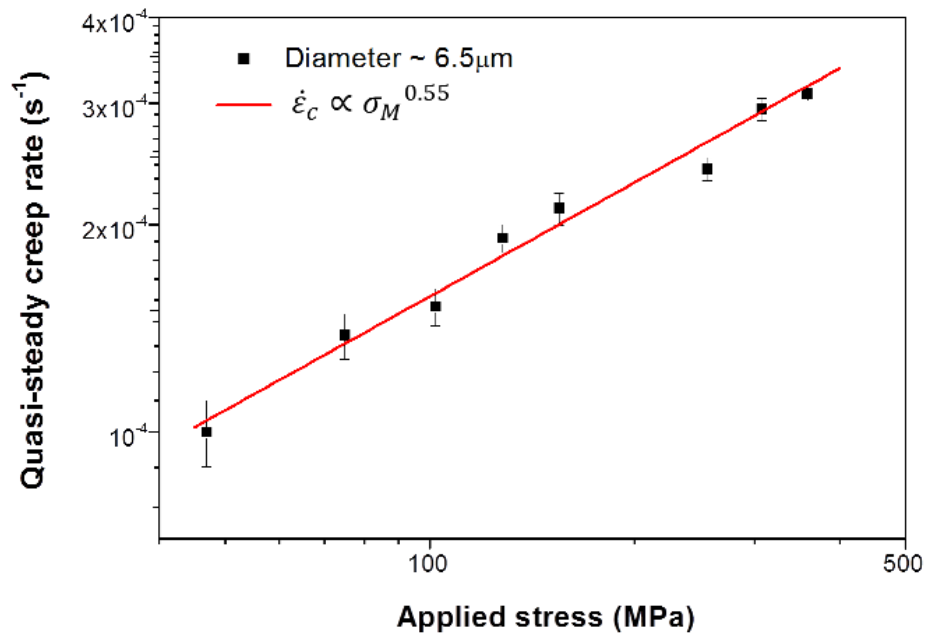

Figure 3 The variation of quasi-steady creep rate with stress for peak-aged single crystalline $6.5 \mu \mathrm{m}$ pillars during the holding regime. 


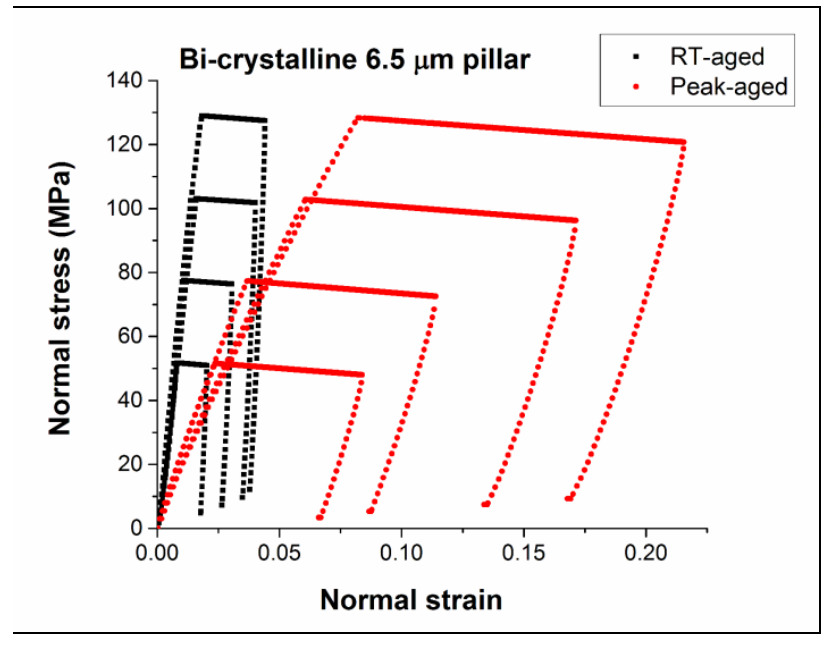

(a)

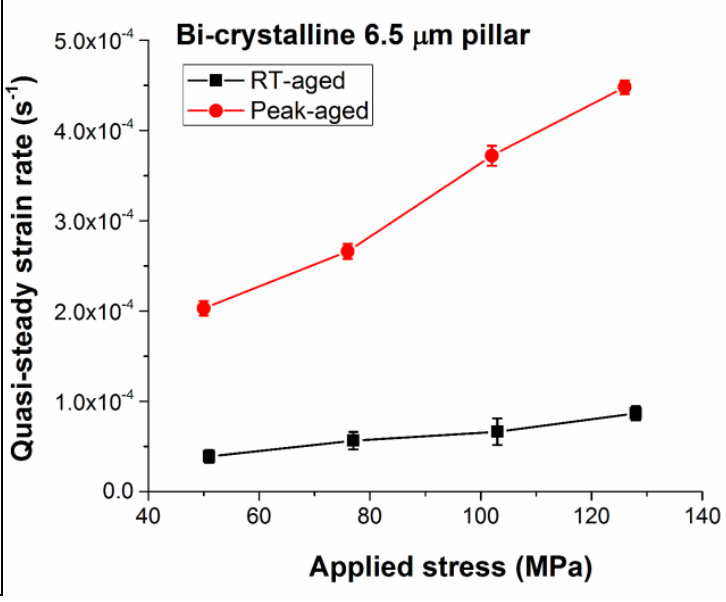

(b)

Figure 4 (a)Stress-strain curves of bi-crystalline $6.5 \mu \mathrm{m}$ pillars fabricated on RT-aged and peakaged duralumin bulk. The holding time at peak loading is 200 seconds for all the tests. (b) Quasisteady strain rate versus applied stress during creep tests.

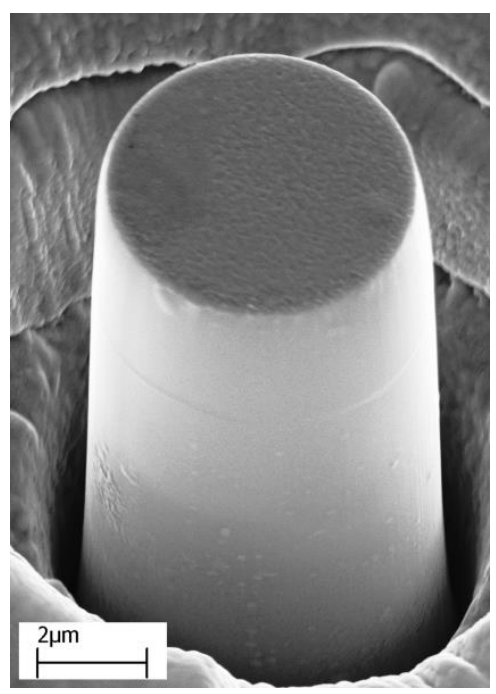

(a)

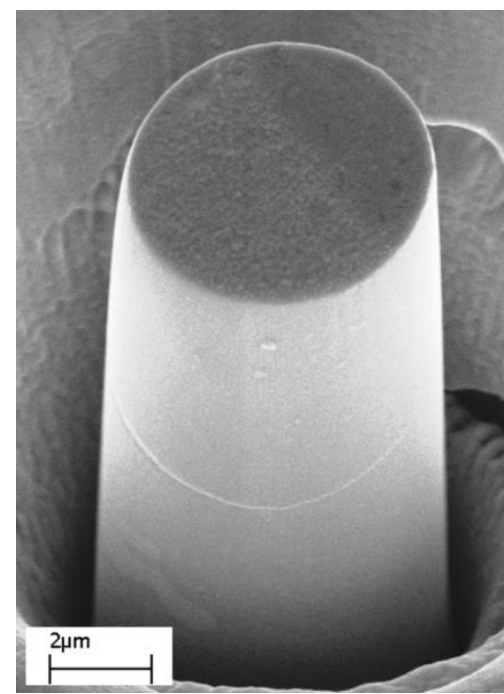

(b)

Figure 5 Deformed SEM images of duralumin bi-crystalline $6.5 \mu \mathrm{m}$ pillars, aged at (a) RT and (b) peak condition respectively, which were undertaken at $30^{\circ}$ tilting. Both of the micro-pillars were deformed after creep tests at $\sim 100 \mathrm{MPa}$. 


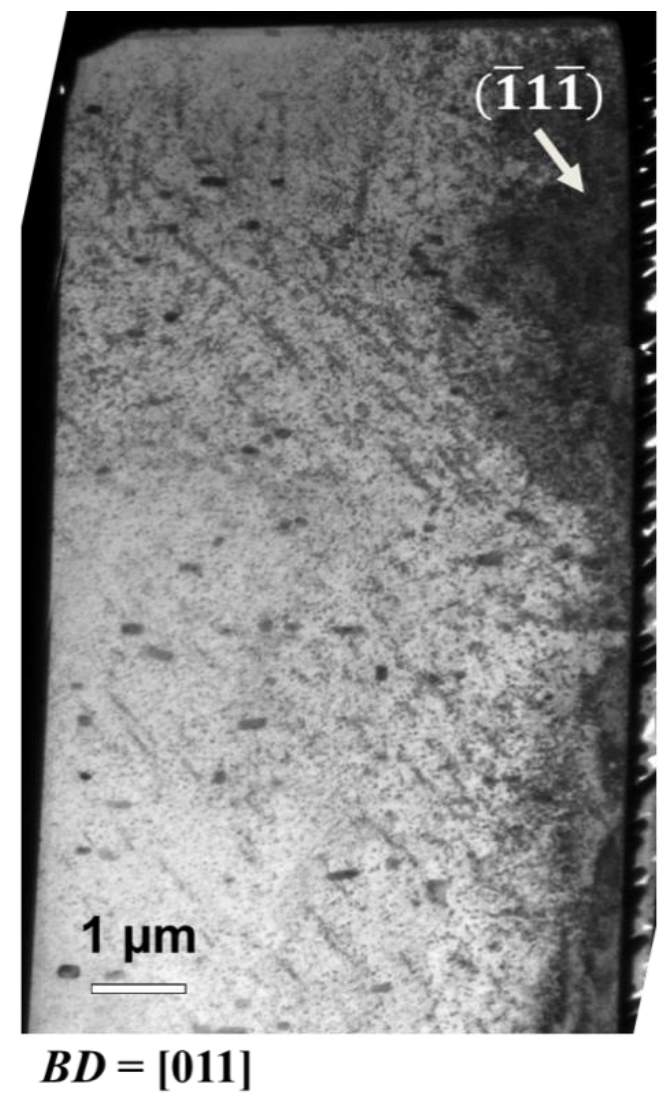

(a)

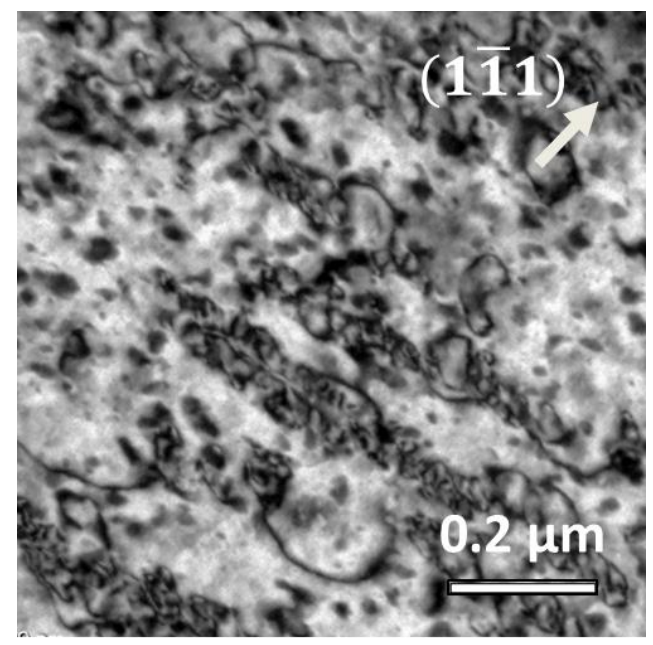

$B D=[011]$

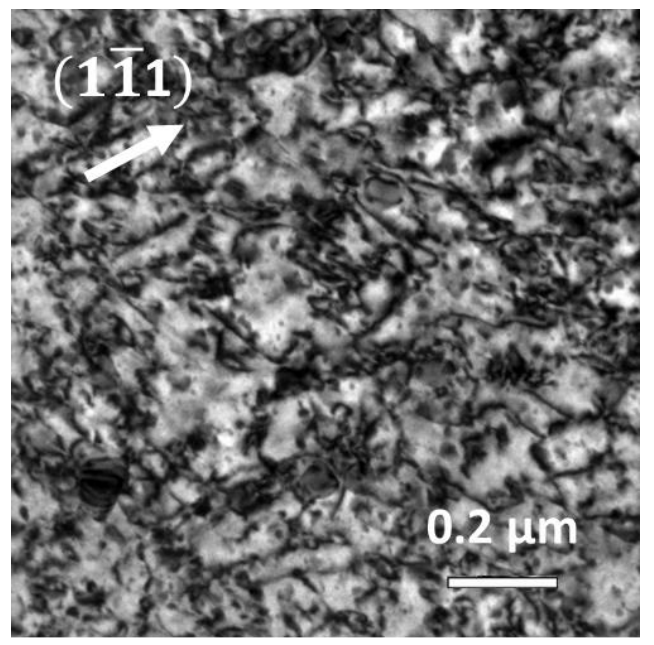

$B D=[011]$

(b)

(c) 
Figure 6 (a) Bright-field TEM montages of a single crystalline $6.5 \mu \mathrm{m}$ duralumin pillar aged at RT. (b) and (c) are high magnification, localized TEM images of single crystalline $6.5 \mu \mathrm{m}$ pillars aged at RT and peak conditions respectively, and the corresponding final strain are 0.013 and 0.056 for (b) and (c).

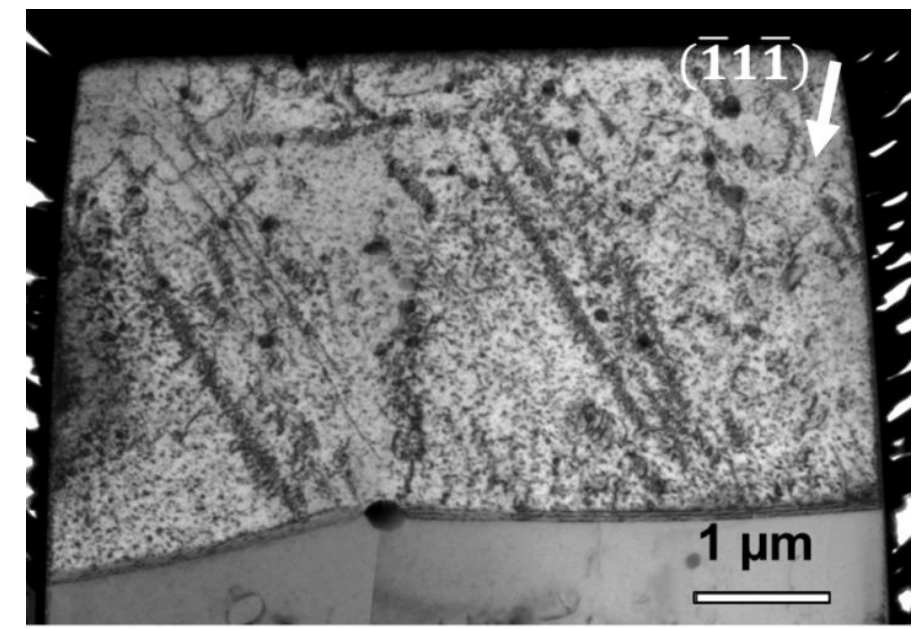

$B D=[\mathbf{1 0 1}]$

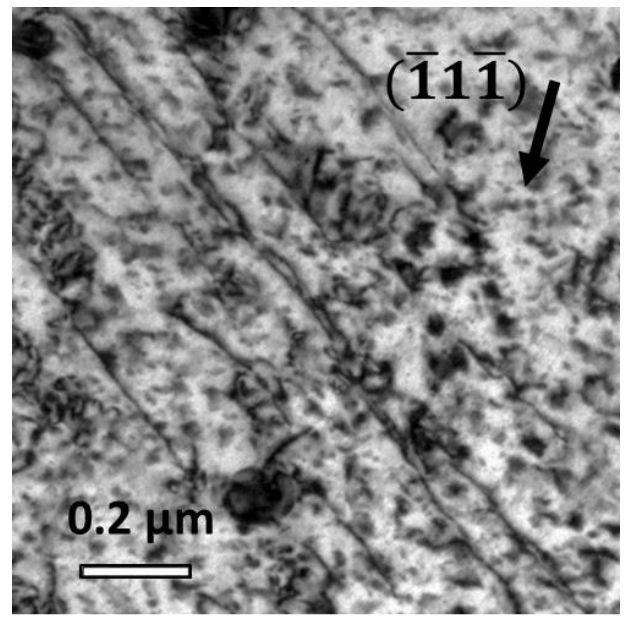

$B D=[101]$

(a)

(b) 


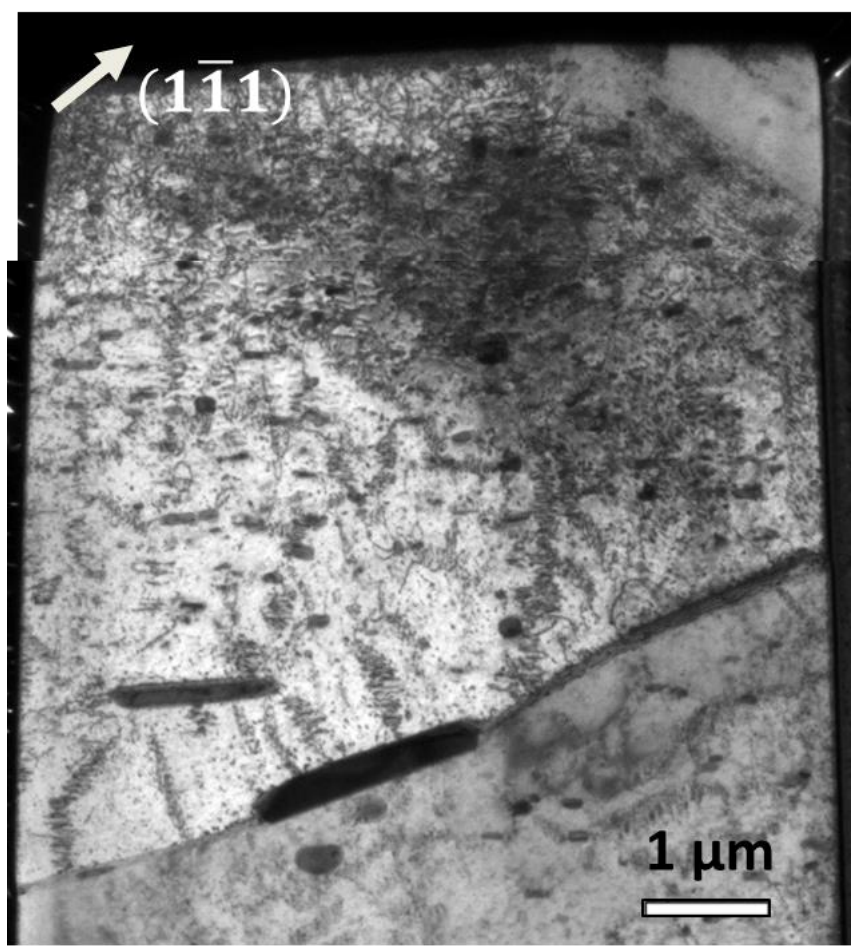

$B D=[011]$

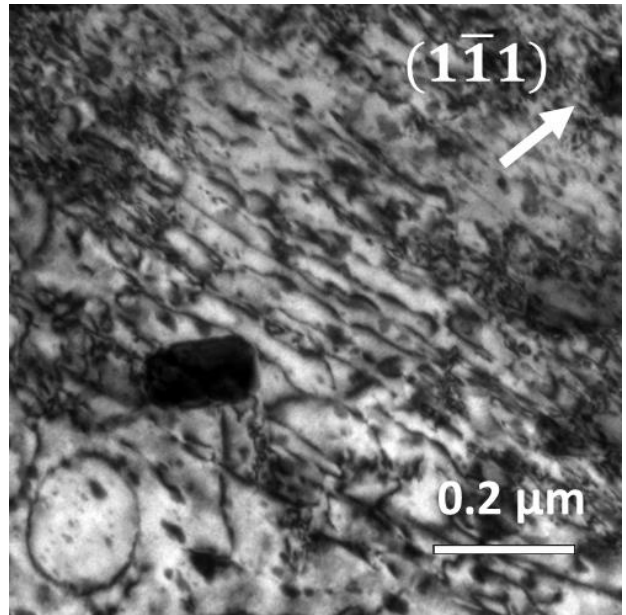

$B D=[011]$

(c)

(d)

Figure 7 (a) and (c) are bright-field TEM montages of bi-crystalline $6.5 \mu \mathrm{m}$ pillars aged at RT and peak conditions respectively, with corresponding final strain of 0.035 and 0.134 . (c) and (d) are high-magnification, local TEM images of the top grain close to pillar's top, corresponding to (a) and (c) respectively. 


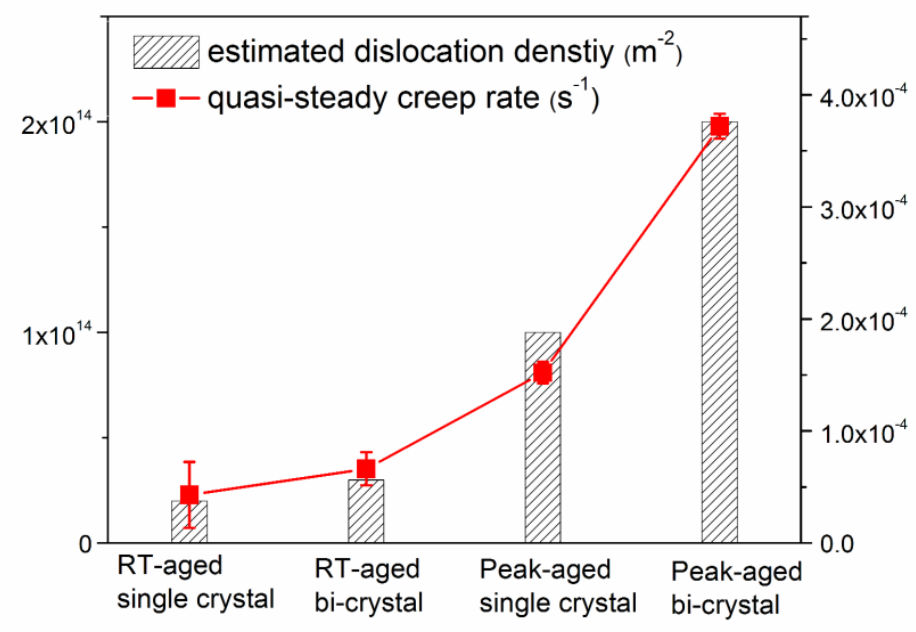

Figure 8 Estimated dislocation densities in duralumin $6.5 \mu \mathrm{m}$ pillars crept at $\sim 100 \mathrm{MPa}$, in comparison with the quasi-steady creep rate.

\section{References}

Afanasyev, K.A., Sansoz, F., 2007. Strengthening in gold nanopillars with nanoscale twins. Nano Lett. 7, 2056-2062.

Afrin, N., Ngan, A.H.W., 2006. Creep of micron-sized Ni3Al columns. Scripta Mater. 54, 7-12. Akarapu, S., Zbib, H.M., Bahr, D.F., 2010. Analysis of heterogeneous deformation and dislocation dynamics in single crystal micropillars under compression. Int. J. Plasticity 26, 239257.

Austin, R.A., McDowell, D.L., 2011. A dislocation-based constitutive model for viscoplastic deformation of fcc metals at very high strain rates. Int. J. Plasticity 27, 1-24.

Burek, M.J., Jin, S.M., Leung, M.C., Jahed, Z., Wu, J., Budiman, A.S., Tamura, N., Kunz, M., Tsui, T.Y., 2011. Grain boundary effects on the mechanical properties of bismuth nanostructures. Acta Mater. 59, 4709-4718.

Choi, I.-C., Kim, Y.-J., Seok, M.-Y., Yoo, B.-G., Kim, J.-Y., Wang, Y., Jang, J.-i., 2013. Nanoscale room temperature creep of nanocrystalline nickel pillars at low stresses. Int. J. Plasticity 41, 53-64.

Deng, C., Sansoz, F., 2009. Size-dependent yield stress in twinned gold nanowires mediated by site-specific surface dislocation emission. Appl. Phys. Lett. 95.

Dimiduk, D.M., Uchic, M.D., Parthasarathy, T.A., 2005. Size-affected single-slip behavior of pure nickel microcrystals. Acta Mater. 53, 4065-4077.

Dimiduk, D.M., Uchic, M.D., Rao, S.I., Woodward, C., Parthasarathy, T.A., 2007. Overview of experiments on microcrystal plasticity in FCC-derivative materials: selected challenges for modelling and simulation of plasticity. Modell. Simul. Mater. Sci. Eng. 15, 135-146. 
Dimiduk, D.M., Woodward, C., LeSar, R., Uchic, M.D., 2006. Scale-free intermittent flow in crystal plasticity. Science 312, 1188-1190.

Dou, R., Derby, B., 2009. A universal scaling law for the strength of metal micropillars and nanowires. Scripta Mater. 61, 524-527.

Dunnwald, J., ElMagd, E., 1996. Description of the creep behaviour of the precipitationhardened material Al-Cu-Mg alloy 2024 using finite element computations based on microstructure mechanical models. Comput. Mater. Sci. 7, 200-207.

El-Awady, J.A., Rao, S.I., Woodward, C., Dimiduk, D.M., Uchic, M.D., 2011. Trapping and escape of dislocations in micro-crystals with external and internal barriers. Int. J. Plasticity 27, 372-387.

Feng, G., Ngan, A.H.W., 2001. Creep and strain burst in indium and aluminium during nanoindentation. Scripta Mater. 45, 971-976.

Frick, C.P., Clark, B.G., Orso, S., Schneider, A.S., Arzt, E., 2008. Size effect on strength and strain hardening of small-scale 111 nickel compression pillars. Mat. Sci. Eng. A-Struct. 489, 319-329.

Greer, J.R., De Hosson, J.T.M., 2011. Plasticity in small-sized metallic systems: Intrinsic versus extrinsic size effect. Prog. Mater. Sci. 56, 654-724.

Greer, J.R., Nix, W.D., 2006. Nanoscale gold pillars strengthened through dislocation starvation. Phys. Rev. B 73.

Greer, J.R., Oliver, W.C., Nix, W.D., 2005. Size dependence of mechanical properties of gold at the micron scale in the absence of strain gradients. Acta Mater. 53, 1821-1830.

Gu, R., Ngan, A.H.W., 2012. Effects of pre-straining and coating on plastic deformation of aluminum micropillars. Acta Mater. 60, 6102-6111.

Gu, R., Ngan, A.H.W., 2013. Size effect on the deformation behavior of duralumin micropillars. Scripta Mater. 68, 861-864.

Gu, X.W., Loynachan, C.N., Wu, Z., Zhang, Y.-W., Srolovitz, D.J., Greer, J.R., 2012. SizeDependent Deformation of Nanocrystalline Pt Nanopillars. Nano Lett. 12, 6385-6392.

Han, S.M., Bozorg-Grayeli, T., Groyes, J.R., Nix, W.D., 2010. Size effects on strength and plasticity of vanadium nanopillars. Scripta Mater. 63, 1153-1156.

Hemker, K.J., Nix, W.D., 2008. Nanoscale deformation - Seeing is believing. Nat. Mater. 7, $97-$ 98.

Jang, D., Cai, C., Greer, J.R., 2011. Influence of Homogeneous Interfaces on the Strength of 500 nm Diameter Cu Nanopillars. Nano Lett. 11, 1743-1746.

Jang, D., Li, X., Gao, H., Greer, J.R., 2012. Deformation mechanisms in nanotwinned metal nanopillars. Nature Nanotech. 7, 594-601.

Jennings, A.T., Gross, C., Greer, F., Aitken, Z.H., Lee, S.W., Weinberger, C.R., Greer, J.R., 2012. Higher compressive strengths and the Bauschinger effect in conformally passivated copper nanopillars. Acta Mater. 60, 3444-3455.

Kazanjian, S.M., Wang, N., Starke, E.A., 1997. Creep behavior and microstructural stability of $\mathrm{Al}-\mathrm{Cu}-\mathrm{Mg}-\mathrm{Ag}$ and Al-Cu-Li-Mg-Ag alloys. Mat. Sci. Eng. A-Struct. 234, 571-574.

Kim, J.-Y., Jong, D., Greer, J.R., 2010. Tensile and compressive behavior of tungsten, molybdenum, tantalum and niobium at the nanoscale. Acta Mater. 58, 2355-2363.

Kim, J.Y., Jang, D.C., Greer, J.R., 2012. Crystallographic orientation and size dependence of tension-compression asymmetry in molybdenum nano-pillars. Int. J. Plasticity $28,46-52$. 
Kloc, L., Cerri, E., Spigarelli, S., Evangelista, E., Langdon, T.G., 1996. Significance of continuous precipitation during creep of a powder metallurgy aluminum alloy. Mat. Sci. Eng. AStruct. 216, 161-168.

Kunz, A., Pathak, S., Greer, J.R., 2011. Size effects in Al nanopillars: Single crystalline vs. bicrystalline. Acta Mater. 59, 4416-4424.

Lee, S.-W., Han, S.M., Nix, W.D., 2009. Uniaxial compression of fcc Au nanopillars on an MgO substrate: The effects of prestraining and annealing. Acta Mater. 57, 4404-4415.

Lee, S.-W., Jennings, A.T., Greer, J.R., 2013. Emergence of enhanced strengths and Bauschinger effect in conformally passivated copper nanopillars as revealed by dislocation dynamics. Acta Mater. 61, 1872-1885

Li, J., Ngan, A.H.W., 2010. Nanoscale fast relaxation events in polyethylene. Scripta Mater. 62, 488-491.

Lumley, R.N., Morton, A.J., Polmear, I.J., 2002. Enhanced creep performance in an Al-Cu-MgAg alloy through underageing. Acta Mater. 50, 3597-3608.

Maass, R., Uchic, M.D., 2012. In-situ characterization of the dislocation-structure evolution in Ni micro-pillars. Acta Mater. 60, 1027-1037.

Maass, R., Van Petegem, S., Ma, D.C., Zimmermann, J., Grolimund, D., Roters, F., Van Swygenhoven, H., Raabe, D., 2009. Smaller is stronger: The effect of strain hardening. Acta Mater. 57, 5996-6005.

Nabarro, F.R.N., Villiers, H.L., 1995. The Physics of Creep: Creep and Creep-resistant Alloy. Taylor \& Francis Press, London.

Ng, K.S., Ngan, A.H.W., 2007. Creep of micron-sized aluminium columns. Philos. Mag. Lett. 87, 967-977.

Ng, K.S., Ngan, A.H.W., 2008a. Stochastic nature of plasticity of aluminum micro-pillars. Acta Mater. 56, 1712-1720.

Ng, K.S., Ngan, A.H.W., 2008b. Stochastic theory for jerky deformation in small crystal volumes with pre-existing dislocations. Philos. Mag. 88, 677-688.

Ng, K.S., Ngan, A.H.W., 2009a. Deformation of micron-sized aluminium bi-crystal pillars. Philos. Mag. 89, 3013-3026.

Ng, K.S., Ngan, A.H.W., 2009b. Effects of trapping dislocations within small crystals on their deformation behavior. Acta Mater. 57, 4902-4910.

Ngan, A.H.W., Ng, K.S., 2010. Transition from deterministic to stochastic deformation. Philos. Mag. 90, 1937-1954.

Nix, W.D., Lee, S.W., 2011. Micro-pillar plasticity controlled by dislocation nucleation at surfaces. Philos. Mag. 91, 1084-1096.

Norfleet, D.M., Dimiduk, D.M., Polasik, S.J., Uchic, M.D., Mills, M.J., 2008. Dislocation structures and their relationship to strength in deformed nickel microcrystals. Acta Mater. 56, 2988-3001.

Oh, S.H., Legros, M., Kiener, D., Dehm, G., 2009. In situ observation of dislocation nucleation and escape in a submicrometre aluminium single crystal. Nat. Mater. 8, 95-100.

Parthasarathy, T.A., Rao, S.I., Dimiduk, D.M., Uchic, M.D., Trinkle, D.R., 2007. Contribution to size effect of yield strength from the stochastics of dislocation source lengths in finite samples. Scripta Mater. 56, 313-316.

Poirier, J.-P., 1985. Creep of Crystals: High-Temperature Deformation Processes in Metals, Ceramics and Minerals. Cambridge University Press, Cambridge. 
Rao, S., Dimiduk, D., Parthasarathy, T., Uchic, M., Tang, M., Woodward, C., 2008. Athermal mechanisms of size-dependent crystal flow gleaned from three-dimensional discrete dislocation simulations. Acta Mater. 56, 3245-3259.

Rao, S.I., Dimiduk, D.M., Tang, M., Parthasarathy, T.A., Uchic, M.D., Woodward, C., 2007. Estimating the strength of single-ended dislocation sources in micron-sized single crystals. Philos. Mag. 87, 4777-4794.

Rinaldi, A., Peralta, P., Friesen, C., Sieradzki, K., 2008. Sample-size effects in the yield behavior of nanocrystalline nickel. Acta Mater. 56, 511-517.

Shan, Z.W., Mishra, R.K., Asif, S.A.S., Warren, O.L., Minor, A.M., 2008. Mechanical annealing and source-limited deformation in submicrometre-diameter Ni crystals. Nat. Mater. 7, 115-119.

Smallman, R.E., Ngan, A.H.W., 2007. Physical Metallurgy and Advanced Materials. Elsevier, Amsterdam.

Starink, M.J., Wang, S.C., 2009. The thermodynamics of and strengthening due to co-clusters: General theory and application to the case of Al-Cu-Mg alloys. Acta Mater. 57, 2376-2389.

Sun, Q., Guo, Q., Yao, X., Xiao, L., Greer, J.R., Sun, J., 2011. Size effects in strength and plasticity of single-crystalline titanium micropillars with prismatic slip orientation. Scripta Mater. 65, 473-476.

Uchic, M.D., Dimiduk, D.M., Florando, J.N., Nix, W.D., 2004. Sample dimensions influence strength and crystal plasticity. Science 305, 986-989.

Volkert, C.A., Lilleodden, E.T., 2006. Size effects in the deformation of sub-micron Au columns. Philos. Mag. 86, 5567-5579.

Wang, S.C., Starink, M.J., 2005. Precipitates and intermetallic phases in precipitation hardening Al-Cu-Mg-(Li) based alloys. Int. Mater. Rev. 50, 193-215.

Wang, S.C., Starink, M.J., 2007. Two types of S phase precipitates in Al-Cu-Mg alloys. Acta Mater. 55, 933-941.

Xu, S., Guo, Y.F., Ngan, A.H.W., 2013. A molecular dynamics study on the orientation, size, and dislocation confinement effects on the plastic deformation of Al nanopillars. Int. J. Plasticity 43, 116-127.

Ye, J., Mishra, R.K., Sachdev, A.K., Minor, A.M., 2011. In situ TEM compression testing of Mg and Mg-0.2 wt.\% Ce single crystals. Scripta Mater. 64, 292-295.

Zhang, J.Y., Liu, G., Sun, J., 2013. Strain rate effects on the mechanical response in multi- and single-crystalline $\mathrm{Cu}$ micropillars: Grain boundary effects. Int. J. Plasticity.

Zhang, Y., Lu, G.H., Wang, T.M., Deng, S.H., Shu, X.L., Kohyama, M., Yamamoto, R., 2006. First-principles study of the effects of segregated Ga on an Al grain boundary. J. Phys.: Condens. Matter 18, 5121-5128.

Zimmermann, J., Van Swygenhoven, H., Marichal, C., Van Petegem, S., Borca, C., Bartova, B., Oveisi, E., Hebert, C., 2012. Slip in directionally solidified Mo-alloy micropillars - Part I: Nominally dislocation-free pillars. Acta Mater. 60, 4604-4613. 